\title{
RESEARCH
}

Open Access

\section{GDF-5 promotes epidermal stem cells proliferation via Foxg1-cyclin D1 signaling}

Xiaohong Zhao ${ }^{1 \dagger}$, Ruyu Bian ${ }^{1 \dagger}$, Fan Wang ${ }^{2}$, Ying Wang ${ }^{1}$, Xue Li ${ }^{1}$, Yicheng Guo ${ }^{1}$, Xiaorong Zhang ${ }^{1}$, Gaoxing Luo ${ }^{1 *}$ and Rixing Zhan ${ }^{1 *}$ (D)

\begin{abstract}
Objective: Epidermal stem cells (EpSCs) can self-renew, which are responsible for the long-term maintenance of the skin, and it also plays a critical role in wound re-epithelization, but the mechanism underlying EpSCs proliferation is unclear. GDF-5, also known as BMP-14, is a member of the BMP family and can be used as a self-renewal supporter. Here, we studied the effects of GDF-5 on mouse EpSCs proliferation mechanism in wound healing.

Methods: Firstly, the effects of GDF-5 on EpSCs proliferation was tested by using CCK8 reagent and PCNA expression was analyzed by Western blotting. Secondly, we screened genes that promote EpSCs proliferation in the FOX and cyclin family by qPCR, and then the protein expression level of the selected genes was further analyzed by Western blotting. Thirdly, siRNA plasmids and pAdEasy adenovirus were transfected or infected, respectively, into mouse EpSCs to detect the effect of target genes on GDF-5-induced cell proliferation. Furthermore, we injected GDF-5 to a deep partial thickness burn mouse model for finding out whether EpSCs proliferation can be detected by immunohistochemical. Finally, the relevant target genes were analyzed by qPCR, immunoblotting, and dual-luciferase reporter gene detection.
\end{abstract}

Results: We discovered that $100 \mathrm{ng} / \mathrm{ml}$ recombinant mouse GDF-5 was the optimal concentration for promoting mouse EpSCs proliferation. Through preliminary screened by qPCR, we found that Foxg1 and cyclin D1 could be the downstream molecules of GDF-5, and the results were confirmed by Western blotting. And the effect of GDF-5 on mouse EpSCs proliferation was adjusted by Foxg1/cyclin D1 in vitro and in vivo. Besides, GDF-5-induced transcription of cyclin D1 was regulated by Foxg1-mediated cyclin D1 promoter activity.

Conclusion: This paper showed that GDF-5 promotes mouse EpSCs proliferation via Foxg1-cyclin D1 signal pathway. It is suggested that GDF-5 may be a new approach to make EpSCs proliferation which can be used in wound healing.

Keywords: GDF-5, Mouse epidermal stem cells, Foxg1, Cell proliferation, Cyclin D1

\section{Introduction}

The epidermis is derived from ectoderm cells during embryonic development, these cells go through a layering process to form basal, spinous, and granular layers [1]. The skin epidermis contains different appendages including sweat glands, hair follicles, and sebaceous glands,

\footnotetext{
*Correspondence: logxw@yahoo.com; zhanrixing@sina.com

${ }^{+}$Xiaohong Zhao and Ruyu Bian contributed equally to this work. 'Institute of Burn Research; State Key Laboratory of Trauma, Burn and Combined Injury; Southwest Hospital, The Third Military Medical University (Army Medical University), Chongqing 400038, China

Full list of author information is available at the end of the article
}

which is responsible for immune regulation, pigmentation, and sensory function [2]. The self-renewal and damage repairing of skin tissue mainly depend on the compensatory proliferation and differentiation of EpSCs [3]. After Billingham and Reynolds firstly reported skin cell transplantation for wound healing in 1952 [4], EpSCs have been used in clinical practice, repairing of burns, acute trauma, and skin damage caused by certain diseases [5-7]. But the expansion of EpSCs always is a choke point in its clinical application. The physiological state of EpSCs can be affected by different signaling

C C The Author(s). 2021 Open Access This article is licensed under a Creative Commons Attribution 4.0 International License, which permits use, sharing, adaptation, distribution and reproduction in any medium or format, as long as you give appropriate credit to the original author(s) and the source, provide a link to the Creative Commons licence, and indicate if changes were made. The images or other third party material in this article are included in the article's Creative Commons licence, unless indicated otherwise in a credit line to the material. If material is not included in the article's Creative Commons licence and your intended use is not permitted by statutory regulation or exceeds the permitted use, you will need to obtain permission directly from the copyright holder. To view a copy of this licence, visit http://creativecommons.org/licenses/by/4.0/ The Creative Commons Public Domain Dedication waiver (http://creativecommons.org/publicdomain/zero/1.0/) applies to the data made available in this article, unless otherwise stated in a credit line to the data. 
pathways, including MAPK (mitogen-activated protein kinase) $[8,9]$, Wnt (wingless) $[10,11]$, and TGF- $\beta$ (transforming growth factor-beta) [12] signaling. BMP (bone morphogenetic protein) belongs to the TGF- $\beta$ family and can stimulate cell proliferation [13].

Extracellular BMP binds with cell membrane receptors to initiate downstream signaling pathways, and the signal molecule is translocated to the nucleus, where it is combined with a nuclear transcription factor to regulate gene expression [12]. According to the report, BMP-4 supports self-renewal by inhibiting MAPK pathways in mouse embryonic stem cells [14]. Growth/differentiation factor 5 (GDF-5) is a BMP family member [15], also known as CDMP-1 and BMP-14. Studies suggest that GDF-5 affects angiogenesis [16], migration [16], apoptosis [17], and differentiation [18] in vitro. Syed H. E and his colleagues also discovered that GDF5-induced p38MAPK signaling in fibroblasts regulates cardiac repairing after myocardial infarction [15]. The predecessors conducted a preliminary study on the effect of GDF-5 in wound repairing [13], so we speculate that the increase of GDF-5 may promote the proliferation of EpSCs, but the specific proliferation mechanism of EpSCs promoted by GDF-5 has not been reported. Recent studies have found that FOX (Fork head box) and cyclin are involved in the promotion of cell proliferation by BMP [19].

FOX is a kind of nuclear transcription factors family. The activity of FOX protein can be regulated by phosphorylation, acetylation, and protease hydrolysis [20]. It is known that PI3K-AKT/PKB (phosphoinositide-3-kinaseprotein kinase $\mathrm{B} / \mathrm{Akt}$ ), TGF $\beta$-Smad and MAPK signaling pathways can affect the level of FOX family proteins [19]. Foxa1, Foxc1, Foxd3, Foxo3, Foxg1, Foxp1, and Foxm1 are associated with cell proliferation [21]. The Foxg1 gene is a dose-sensitive gene, and it can antagonize the proapoptotic effect of Foxo3 [22] and promote hepatocellular carcinoma epithelial-mesenchymal transition [23]. As Shasha Zhang's reported, knocking out the Foxg1 gene will increase differentiation of newborn mouse cells [24]. Studies have found that cyclin D plays an important role in cell proliferation, which has three subfamilies: cyclin D1, cyclin D2, and cyclin D3. It mainly initiates signal cascade after binding and activating CDK (4 or 6) (cyclindependent kinase 4 or 6 ) which promoting cell proliferation $[25,26]$. Julie A. Siegenthaler reported that Foxg1 was associated with cyclin in promoting intermediate progenitor cell proliferation [27]. Besides, the Wnt/cyclin D1 pathway has a dedifferentiating effect for differentiated epidermal cells [28]. In our previous research, we found that cyclin D1 is an important downstream signaling molecule in the proliferation of EpSCs [29].

In this paper, we conducted an integral study in vitro and in vivo conditions and carried out necessary tests. We sought to elucidate the effects of GDF-5 on mouse
EpSCs proliferation mechanisms in wound healing. We also hope to find new wound repair targets through our research and provide new strategies for clinical research.

\section{Methods and reagents \\ Animals}

Both male and female C57BL/6 mice were used in this study. They were obtained from the Experimental Animal Department of the Army Military Medical University, China. All animal procedures were approved by the Committee on the ethics of Animal Experiments of the Third Military Medical University and were conducted in accordance with the guidelines of the Experimental Animal Department of the Army Military Medical University. The animals were individually housed in plastic cages under standard conditions (temperature, $25^{\circ} \mathrm{C}$; relative humidity, 50\%; and circadian rhythm, $12 \mathrm{~h}$ ). Animals were provided cold boiled water and rodent food, and allow them to acclimate to the facility for 1 week before the experiment. All surgeries were performed under $0.1 \%$ sodium pentobarbital anesthesia, and all efforts were made to minimize suffering. The wound needs to be covered with sterile oil gauze to prevent infection.

\section{Preparation of mouse primary EpSCs}

The preparation of primary EpSCs from newborn mice (0-2 days) was described in our previous studies [30]. Firstly, the neonatal mice were euthanized by cervical dislocation. Secondly, soaked for $1 \mathrm{~min}$ in $75 \%$ ethanol and washed twice with sterile PBS. Thirdly, the back skin was separated with sterile surgical instruments and incubated with $0.5 \%$ dispase II (Gibco, \#17105041) overnight at $4{ }^{\circ} \mathrm{C}$. Next, the skin was washed three times with sterile PBS and separated carefully and the epidermis was dissociated with $0.25 \%$ Trypsin (Gibco, \#25200056) at $37^{\circ} \mathrm{C}$ for $10 \mathrm{~min}$; the single-cell suspension was passed through a $70-\mu \mathrm{m}$ filter (BD Falcon \#352350) into a sterile $15-\mathrm{ml}$ tube. Then, the cell suspension was centrifuged at $1000 \mathrm{rpm}$ for $5 \mathrm{~min}$, removed supernatant, and resuspended cells in K-SFM (Gibco, 10744019) supplemented with $0.2 \mathrm{ng} / \mathrm{ml}$ recombinant mouse EGF (stem cell, \#78016), $100 \mathrm{ng} / \mathrm{ml}$ Cholera toxin, $30 \mathrm{mg} / \mathrm{ml} \mathrm{BPE} \mathrm{(bo-}$ vine pituitary extract), $0.05 \mathrm{mM}$ calcium chloride, and $100 \mathrm{U} / \mathrm{ml}$ of streptomycin and penicillin. Follow $2.5 \times$ $10^{\wedge} 6$ cells/T25 to quickly adhere to the bottom for 10 min, change the medium. Finally, the cells were cultured and the medium was changed every $2-3$ days.

\section{Flow cytometry analysis}

When second-generation (P2) cells confluence become $\sim 70 \%$ after TrypLE ${ }^{\mathrm{Tw}}$ select (Gibco, \#12563029) passaged. Flow cytometry analysis of the purity of passaged EpSCs: Collect EpSCs at a density of $10^{\wedge} 6 \mathrm{cell} / \mathrm{ml}$, and then add antibodies, Santa SC23372-CD71-PE $5 \mu \mathrm{l} / \mathrm{EP}$ tube, Santa 
SC19622-CD49f-FITC $5 \mu \mathrm{l} / \mathrm{EPT}$ tube, test after $60 \mathrm{~min}$ incubation at $4{ }^{\circ} \mathrm{C}$. Finally, resuspended in $0.5 \mathrm{ml}$ of PBS, and then subjected to flow cytometry analysis.

\section{Cell proliferation assay}

Possible proliferation was assessed by cell viability using Cell Counting Kit-8 (CCK-8) (Beyotime, C0038, China) according to the manufacturer's instructions. When first-generation (P1) cells confluence become $\sim 70 \%$, collect EpSCs at a density of $2 \times 10^{\wedge} 5 \mathrm{cell} / \mathrm{ml}$. Then, the $2000 \mathrm{EpSCs}$ were seeded in 96-well plates $(100 \mu \mathrm{l} /$ well $)$ and treated with $0,1,50,100,500$, and $1000 \mathrm{ng} / \mathrm{ml}$ of GDF-5 (Beyotime, P6193, China) for 12, 24, 48, and 72 h. After that, $10 \mu \mathrm{l} \mathrm{CCK-8} \mathrm{solution} \mathrm{was} \mathrm{added} \mathrm{to} \mathrm{96-well}$ and incubated for $2-4 \mathrm{~h}$ at $37{ }^{\circ} \mathrm{C}$. Absorbance was measured at $450 \mathrm{~nm}$ with a microplate reader (Spectra Max 190; Molecular Devices).

\section{Adenovirus infection and siRNA transient transfection}

Adenovirus transfection and siRNA interference protocol were as previously described [31, 32]. Adenovirus transfection was made when EpSCs reached 70\% confluence and then aspirated the medium and added fresh medium. After that, added $10 \mu \mathrm{l} \mathrm{Myc}$ adenovirus and $10 \mu \mathrm{l}$ Foxg1 adenovirus and $10 \mu \mathrm{l}$ empty vector to each group. After $24 \mathrm{~h}$ ' transfection, we observed the fluorescence intensity and expression ratio with a fluorescence microscope and changed the medium. After $48 \mathrm{~h}$ ' transfection, cells were collected for subsequent experiments. Specific cyclin D1 siRNA and control siRNA were purchased from Thermo Fisher Scientific. EpSCs preparation method is as described above. Mouse EpSCs were transfected with siRNA according to the manufacturer's instructions. The efficiency of siRNA interference was analyzed by the following Western blotting.

\section{Western blotting (WB)}

The levels of C Foxg1, cyclin D1, PCNA, and GAPD $\mathrm{H}$ protein were detected by WB. GDF-5 was treatment EpSCs for $24 \mathrm{~h}$, and then collect cells. EpSCs protein samples were prepared using RIPA lysis buffer (Beyotime, P0013B, China), which contained protease and phosphatase inhibitors. It was quantified using BCA protein evaluation kit (Beyotime, P0012S, China). Next, $30 \mu \mathrm{g} / \mathrm{each}$ sample of protein was loaded onto 10\% SDS-PAGE and transferred to PVDF membrane (Beyotime, FFP24, China). Then, the membrane was blocked with a $5 \%$ milk solution $(\mathrm{w} / \mathrm{v})$ at room temperature for $2 \mathrm{~h}$. Then, the primary antibody was incubated overnight at $4{ }^{\circ} \mathrm{C}$. The primary antibody was diluted according to the following ratio: PCNA (ab92552, 1:5000), Foxg1 (ab196868, 1:5000), cyclin D1 (ab16663, 1:5000), and GAPDH (ab181606, 1:10,000). All antibodies were purchased from Abcam
(Cambridge, Massachusetts, USA). After incubating the primary antibody, the membrane was washed three times and incubated with goat anti-rabbit IgG $(\mathrm{H}+\mathrm{L})(1: 10,000)$ (Abcam, ab6702) for $1 \mathrm{~h}$. The bands were visualized by using the BeyoECL Plus (Beyotime, P0018M, China), and the bands were detected using Image Quant LAS $4000 \mathrm{~s}$ (GE, USA) [33].

\section{Real-time quantitative PCR (qPCR)}

GDF-5 treatment EpSCs for $24 \mathrm{~h}$, and then collect cells. We used RNAiso Plus (Takara, \# 9109) to extract RNA following the instructions, and measured the A260 and A280 values of the sample. Next, qPCR was performed. The first step is to remove the genomic DNA $\left(42^{\circ} \mathrm{C}, 2\right.$ min; $4^{\circ} \mathrm{C}$ hold), the second step is the reverse transcription reaction $\left(37^{\circ} \mathrm{C}, 15 \mathrm{~min} ; 85^{\circ} \mathrm{C}, 5 \mathrm{~s} ; 4^{\circ} \mathrm{C}\right.$ hold), and finally the real-time PCR reaction $\left(95^{\circ} \mathrm{C}, 30 \mathrm{~s}\right.$; go to 39 (40 cycles), $95^{\circ} \mathrm{C}, 5 \mathrm{~s}, 60^{\circ} \mathrm{C}, 30 \mathrm{~s}$; melt curve). The primescript RT reagent kit with gDNA Eraser (Takara, \# RR047A) and TB green Premix Ex Taq (Takara, \# RR820A) were used. Real-time PCR analysis of mouse cDNA was performed using the 7500 qPCR System

Table 1 Primers for the RT-qPCR

\begin{tabular}{|c|c|c|c|}
\hline Primer name & Sequence (5' to $\left.3^{\prime}\right)$ & Length & $\operatorname{Tm}\left({ }^{\circ} \mathrm{C}\right)$ \\
\hline GAPDH-F & GGTTGTCTCCTGCGACTTCA & 20 & 57.5 \\
\hline GAPDH-R & TGGTCCAGGGTTTCTTACTCC & 21 & 56.5 \\
\hline Foxa1-F & TTACAAGGATGCCTCTCCA & 19 & 52.6 \\
\hline Foxa1-R & TGGCTCTCTGAAAAGCAAG & 19 & 52.4 \\
\hline Foxc1-F & GGATCGGCTTGAACAACT & 18 & 52.4 \\
\hline Foxc1-R & AGAGTGCCGGGAATAGG & 17 & 54.0 \\
\hline Foxd3-F & CGTAGAGAAGCGTCGAGGA & 19 & 56.6 \\
\hline Foxd3-R & GGCAAAGGAGGTGTGAGTG & 19 & 56.5 \\
\hline Foxg1-F & AACGGGCTGAGTGTGGA & 17 & 58.8 \\
\hline Foxg1-R & CAGGGGTTGAGGGAGTAGG & 19 & 57.6 \\
\hline Foxo3-F & GAGGATTCGGCCATGCT & 17 & 55.4 \\
\hline Foxo3-R & TTCCTTGGTTGCCCAGAG & 18 & 55.1 \\
\hline Foxp1-F & TGCGCTGGACGATAGAA & 17 & 53.4 \\
\hline Foxp1-R & ATGCAGGTGGGTCATCA & 17 & 53.5 \\
\hline Cyclin C-F & ATGCTTGGTAATTGATTTGCT & 21 & 49.5 \\
\hline Cyclin C-R & CAGGGGTTGAGGGAGTAGG & 19 & 57.6 \\
\hline Cyclin D1-F & ACCCTGACACCAATCTCCT & 19 & 55.6 \\
\hline Cyclin D1-R & СTCCTTCTGCACGCACTT & 18 & 55.6 \\
\hline Cyclin D2-F & CCGTTCTTGGCTCTGGT & 17 & 55.1 \\
\hline Cyclin D2-R & AGGCACCTGTTGAAACTGA & 19 & 53.9 \\
\hline Cyclin D3-F & AAACCACGCCCCTGACT & 17 & 57.2 \\
\hline Cyclin D3-R & AGGTCCCACTTGAGCTTCC & 19 & 57.4 \\
\hline Cyclin E-F & CCCAAGTCCTGAGCCAT & 17 & 54.7 \\
\hline Cyclin E-R & TCGGAGCCACCTTCTTC & 17 & 54.5 \\
\hline
\end{tabular}


(Applied Biosystems). GAPDH serves as an internal reference. Primers synthesized by Sangon Biotech (Shanghai), and primer sequences are listed in Table 1 .

\section{Dual-luciferase assay}

Follow our previous method [32]. Firstly, construction of reporter gene plasmid. The mouse cyclin D1 promoter sequence was cloned into pGL3-basic plasmid vector to obtain pF1, pF2, pF3, pF4, pF5, and pF6 plasmid. $\mathrm{Mu}-$ tated $\mathrm{pF} 2$ was generated by using the Mutant Best Kit (Takara, China). Secondly, transfect cells. At $48 \mathrm{~h}$ after pAdEasy-Foxg1 or pAdEasy-Myc transfection, the cells were transfected with the above luciferase reporter expression vectors using Lipofectamine 2000 for the promoter assay, respectively. And then, we used a multifunctional microplate reader to detect the expression level of the reporter gene according to the manufacturer's instructions (Promega, E2940).

\section{EpSCs proliferation assay in vivo}

A deep partial-thickness burn mouse model was made as follows description [34], and EpSCs were labeled with BrdU in mouse skin. Neonatal C57BL/6 mice were intraperitoneally injected with $\mathrm{BrdU}(50 \mathrm{mg} / \mathrm{kg}$ body weight, Sigma) twice daily for 3 days, beginning on day 3 after birth. Skin cells retaining BrdU were identified as EpSCs after 7 weeks. Next, an anesthetic was injected intraperitoneally. Each gram of body weight was injected with $0.1 \%$ sodium pentobarbital at a dose of $10 \mu \mathrm{l}$; a metal plate (Shandong Academy of Medical Science, China) with a diameter of $1.5 \mathrm{~cm}$ and weight of $0.5 \mathrm{~kg}$ was used to induce deep partialthickness burns. The metal plate was heated to $70^{\circ} \mathrm{C}$ and was placed evenly on the shaved mouse dorsum for $3 \mathrm{~s}$ to form a scald model. The skin wounds were covered with sterile oil gauze to prevent infection; mice were individually housed in plastic cages under standard conditions.

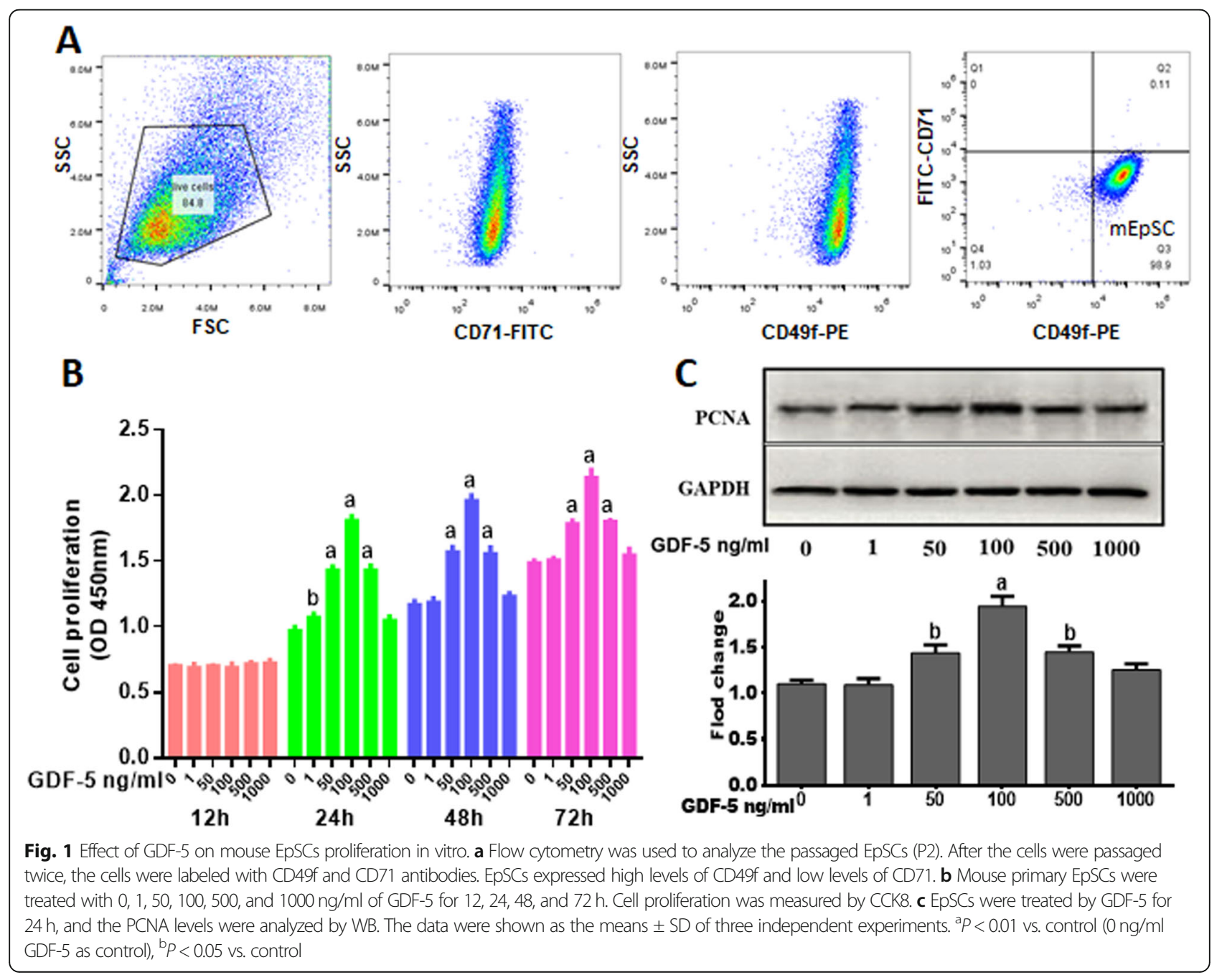


The 36 mice were divided randomly into 6 groups: control (normal saline), pAdEasy-Myc, cyclin D1 siRNA, GDF-5, pAdEasy-Foxg1 + GDF-5, and cyclin D1 siRNA + GDF-5. After modeling, control group (normal saline $0.05 \mathrm{ml} / \mathrm{g}$ body weight, i.p.), pAdEasy-Myc and pAdEasyFoxg1 and cyclin D1 siRNA ( $0.5 \mathrm{ml}$ of PBS containing $2.5 \times 10^{8}$ PFU virus, wound margin five points, s.c.), GDF-5 (0.05 ml/g body weight, i.p.), and GDF-5's concentration is $10 \mu \mathrm{g} / \mathrm{ml}$ in normal saline. Mice were sacrificed after $24 \mathrm{~h}$ and using immunofluorescence assay BrdU and PCNA.

\section{Tissue immunofluorescence analysis}

An anesthetic was injected intraperitoneally. Each gram of body weight was injected with $0.1 \%$ sodium pentobarbital at a dose of $10 \mu \mathrm{l}$, and the mouse was euthanized by cervical dislocation. The wound was biopsy, fixed in
$4 \%$ paraformaldehyde, and cut into $4 \mu \mathrm{m}$ slices. Next, antigen retrieval was performed using citrate buffer in a pressure cooker at $95^{\circ} \mathrm{C}$ for $30 \mathrm{~min}$ and each group was blocked in 10\% goat serum (16210064; Gibco) for 30 min at $37^{\circ} \mathrm{C}$. Then, antibody incubation PCNA (ab92552,1:1000) at $4{ }^{\circ} \mathrm{C}$ overnight. And then drop the corresponding fluorescent secondary antibody (Goat Anti-Rabbit IgG H\&L (Cy5 ${ }^{\circ}$ (ab6564)), DAPI counterstain. Finally, dehydration and fix the mount, confocal laser observation.

\section{Statistical methods}

All data were presented as the mean \pm standard deviation (SD) with at least three independent experiments and analyzed using GraphPad Prism 7.0 software. Statistical significance was evaluated by one-way ANOVA or $t$ test. $P<0.05$ was considered statistically significant.

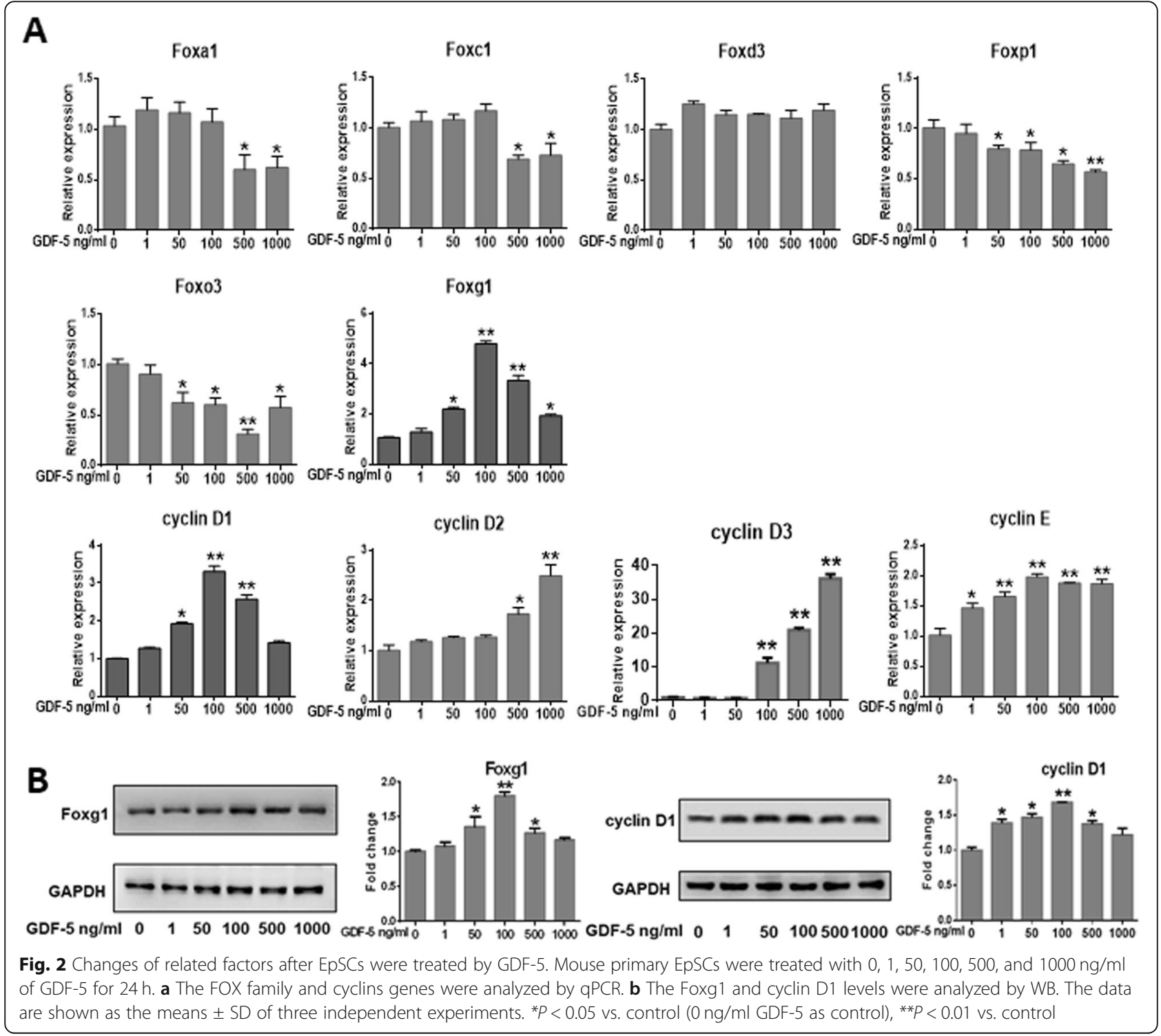




\section{Results}

\section{Effect of GDF-5 on mouse EpSCs proliferation}

Mouse EpSCs were defined as our previously described $[31,35]$. The purity of EpSCs was analyzed by flow cytometry, as shown in Fig. 1a, and the proportion of EpSCs is about 99\%. To illustrate the effect of GDF-5 on mouse EpSCs proliferation, we used CCK-8 assay the proliferation effect of GDF-5 at different time points, and the results showed that $24 \mathrm{~h}$ has the best effect on promoting cell proliferation (0.84-fold) when GDF-5 was $100 \mathrm{ng} / \mathrm{ml}$ (Fig. 1b), so $24 \mathrm{~h}$ was used in the following study. Because the PCNA is a marker that reflects the state of cell proliferation [36], our further analysis of GDF-5 promoting EpSCs proliferation at $24 \mathrm{~h}$ found that the proliferationassociated PCNA protein was significant at $100 \mathrm{ng} / \mathrm{ml}$ $(P<0.01)$ in response to GDF-5 (Fig. 1c).
The possible downstream molecules of GDF- 5

In order to detect the possible downstream molecules of GDF-5, we consulted references and found FOX/cyclin may be the downstream molecules of GDF-5 [19]. Firstly, we screened downstream genes in the FOX and cyclins family, the results discovered that Foxg1 and cyclin D1 were a dose-dependent relationship with GDF-5. In addition, Foxg1 expression increased to 4.79-fold and cyclin D1 increased to 3.31-fold when the concentration of GDF-5 was $100 \mathrm{ng} / \mathrm{ml}$ (Fig. 2a). Secondly, the protein levels of Foxg1 and cyclin D1 in mouse EpSCs treated by GDF- 5 were detected by WB. The results showed that there was a dose-dependent relationship between cells treated with GDF-5 and Foxg1/cyclin D1 protein expression. Moreover, Foxg1 increased to 1.79-fold and cyclin D1 increased to 1.68-fold when the optimal concentration of GDF-5 was $100 \mathrm{ng} / \mathrm{ml}(P<0.01)$ (Fig. 2b).

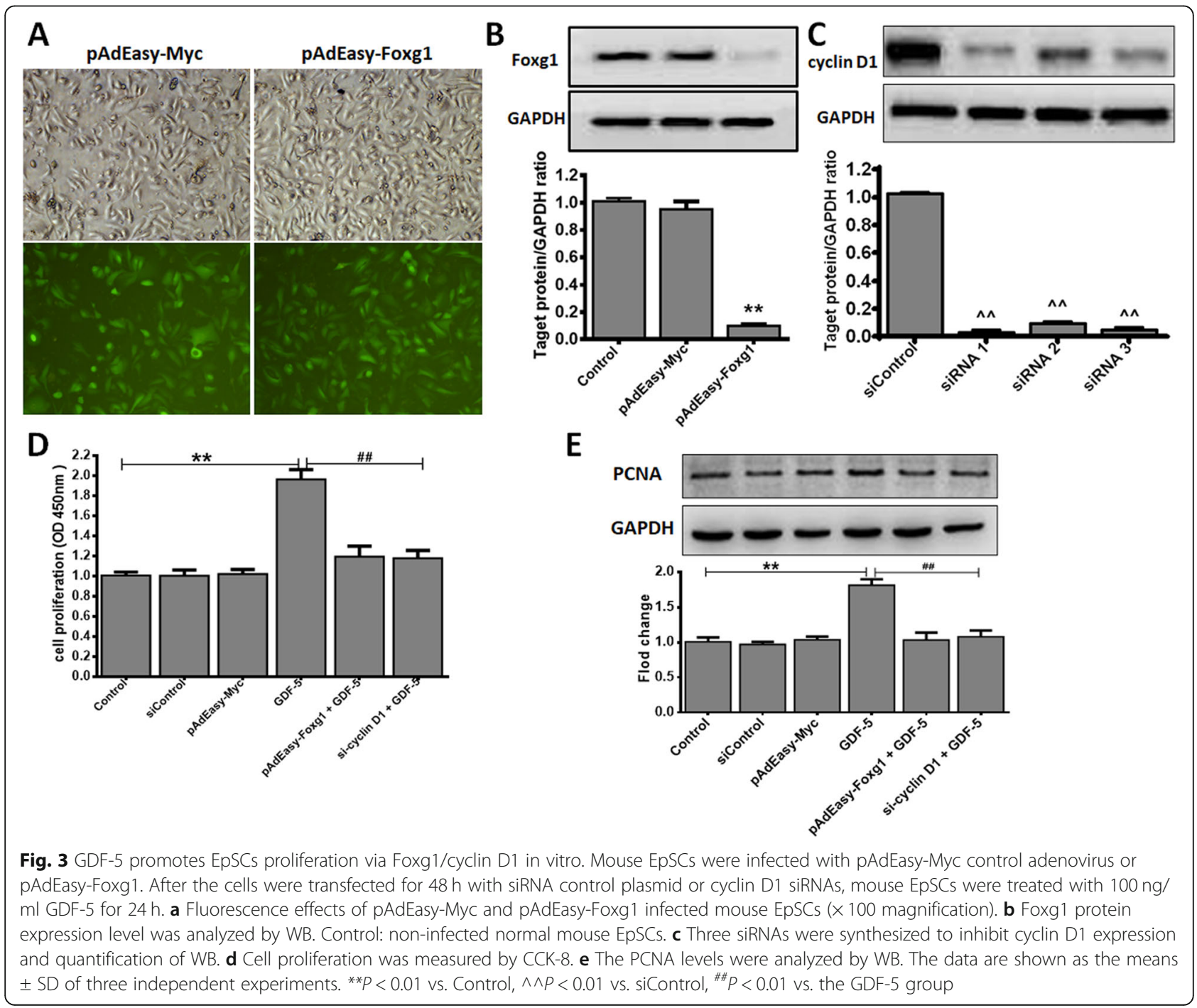




\section{GDF-5 promotes EpSCs proliferation via Foxg1/cyclin D1} in vitro

The above part proved that Foxg1 and cyclin D1 are the downstream molecules of GDF-5. Here we discuss the role of Foxg1 and cyclin D1 in GDF-5 promotes cell proliferation. We used adenovirus and siRNA infection technology to verify the interrelationship of Foxg1/cyclin D1 during cell proliferation. The pAdEasy-Myc transfection mouse EpSCs as control virus, the results showed that pAdEasy-Foxg1 and pAdEasy-Myc had a similar transfection efficiency, reaching to $90 \%$ and $95 \%$ (Fig. 3a), which indicated that each adenovirus successfully infected mouse EpSCs. The pAdEasy-Foxg1 group's Foxg1 expression was reduced by $89 \%(P<0.01)$ compared to the pAdEasy-Myc group, and there was no significance between the pAdEasy-Myc and the control group (Fig. 3b). Three siRNAs were synthesized to inhibit cyclin D1 gene expression. As shown in Fig. 3c, the siRNA1 $(P<$ 0.01 ) with the best silencing efficiency was selected for subsequent research. Finally, mouse EpSCs were treated with $100 \mathrm{ng} / \mathrm{ml}$ GDF- 5 or not treated for $24 \mathrm{~h}$, and cell proliferation was evaluated by CCK- 8 assay and PCNA protein analysis. Figure 3d and e showed that the GDF-5 group had a significant proliferation compared with other groups. In addition, the EpSCs proliferation was inhibited of pAdEasy-Foxg1 + GDF-5 group reduced 0.78 and cyclin D1 siRNA + GDF-5 group reduced 0.73 compared with GDF-5 group (Fig. 3e).

\section{The effect of GDF-5 on mouse EpSCs proliferation via Foxg1/cyclin D1 in vivo}

To analyze the effect of GDF-5 on EpSCs proliferation in vivo, BrdU-labeled EpSCs and mouse model of burn injury were established as our previously described [29]. $\mathrm{BrdU}^{+}$and $\mathrm{PCNA}^{+}$EpSCs were presented by immunochemistry in the regenerated epidermis, and the doublepositive EpSCs were counted in the different reepithelialization area. As can be seen from (Fig. 4a, b), the number of double-positive cells increased to 40.18fold in the GDF-5 group compared with the control group; the results showed that GDF-5 can promote EpSCs proliferation in vivo. However, the doublepositive cells reduced 16.68 and 11.72 in the cyclin D1 siRNA + GDF-5 group and the pAdEasy-Foxg1 + GDF-5 group compared with the GDF-5 group, respectively. The data showed that the pAdEasy-Foxg1 and cyclin D1 siRNA abolished the effect of GDF-5 on the number of double-positive cells in the regenerated epidermis. Moreover, the double-positive cells increased in the pAdEasy-Foxg1+GDF-5 group and the cyclin D1+

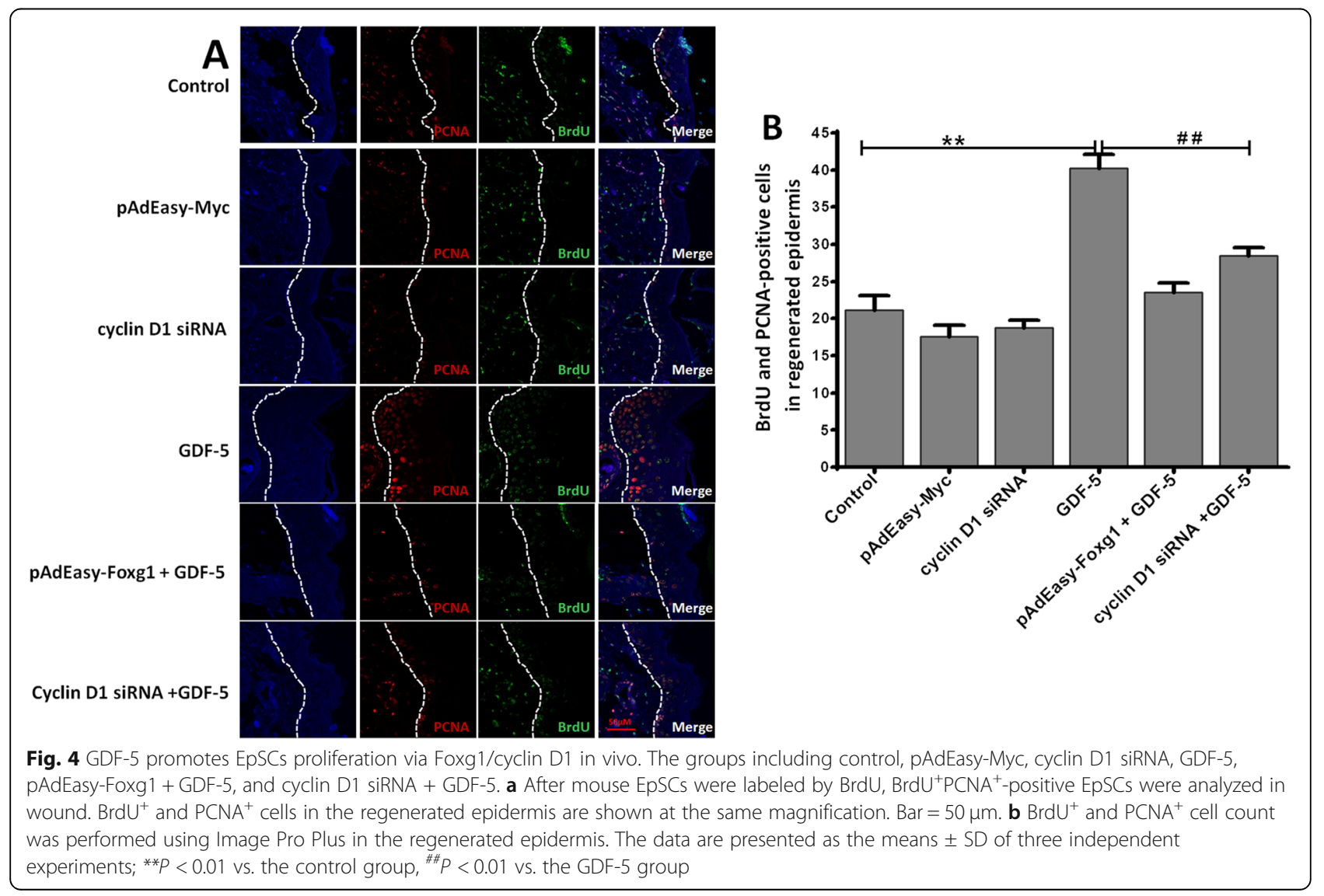




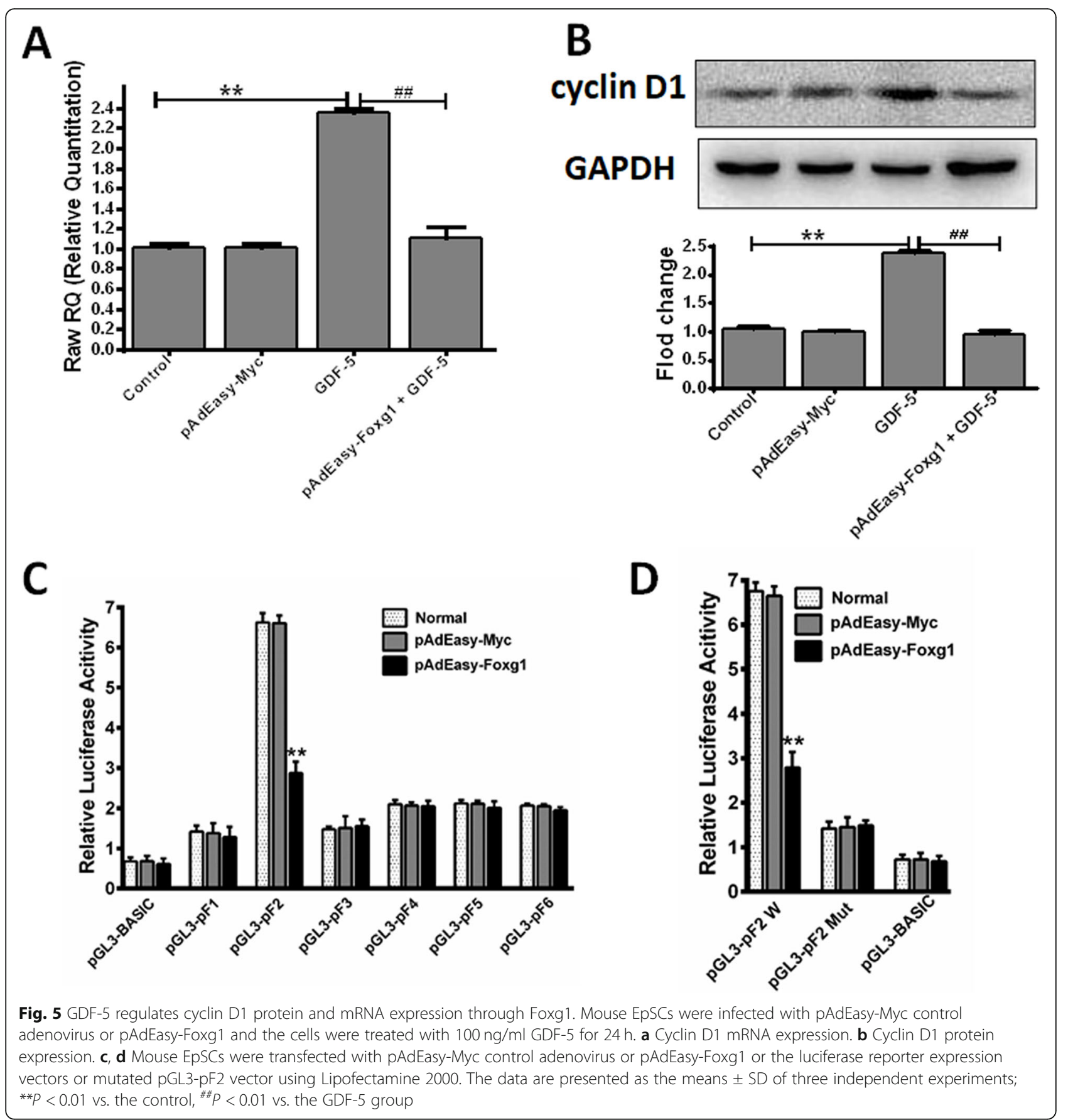

GDF-5 group compared with the control group, but the difference is not obvious.

GDF-5 regulates cyclin D1 expression by Foxg1 and regulates transcriptional activity of the cyclin D1 gene promoter

In order to analyze the transcription relationship between Foxg1 and cyclin D1, qPCR was used to detect cyclin D1 mRNA, and WB was used to detect cyclin D1 protein expression in the presence of pAdEasy-Foxg1.
As can be seen from Fig. 5a, the expression of cyclinD1 mRNA in the GDF-5 group increased to 2.34-fold compared with the control group $(P<0.01)$, but the cyclin D1 mRNA expression of pAdEasy-Foxg1 + GDF- 5 group was reduced back to the control level. At the same time, the cyclin D1 protein expression level also had the same trend (Fig. 5b). This showed that pAdEasy-Foxg1 blocked cyclin D1 expression. Next, we hypothesized that pAdEasy-Foxg1 inhibits cyclin D1 by exerting inhibitory activities to the cyclin D1 promoter. We 
constructed a pGL3-cyclin D1 (pF1, pF2, pF3, pF4, pF5, pF6) luciferase reporter gene expression vector. The dual-luciferase assay revealed that pAdEasy-Foxg1 significantly inhibited the activity of the cyclin D1 promoter (Fig. 5c). However, the mutant pGL3-pF2 did not respond to the pAdEasy-Foxg1 agonists (Fig. 5d).

\section{Discussion}

At present, the effect of GDF-5 on wound healing has been reported [13, 15]. However, its specific mechanism for wound repairing is still unclear. In this paper, we discovered that GDF-5 promoted mouse EpSCs proliferation via the Foxg1/cyclin D1 signaling pathway in vivo and in vitro.

Other studies had reported that GDF-5 promote cell proliferation [13]; in this study, we found that GDF-5 can directly increase the number of EpSCs in vitro. We detected the effect of GDF-5 on EpSCs when the concentration of exogenous GDF- 5 changed from 0 to 1000 $\mathrm{ng} / \mathrm{ml}$ by CCK- 8 assay at $12 \mathrm{~h}, 24 \mathrm{~h}, 48 \mathrm{~h}$, and $72 \mathrm{~h}$. The results showed that EpSCs had the best cell proliferation effect after being treated with $100 \mathrm{ng} / \mathrm{ml}$ exogenous GDF-5 (Fig. 1b), the effective concentration of GDF-5 on cells is similar to the previous reports [37]. In vivo, through the study of a deep partial-thickness burn mouse model, we found that GDF-5 promoted the proliferation of EpSCs, which is consistent with the results of in vitro experiments (Fig. 4a, b). In addition, PCNA is a marker that reflects the state of cell proliferation [36]; we tested the expression of PCNA protein after different concentrations of GDF-5 treatment for $24 \mathrm{~h}$ (Fig. 1c). Combining the results of cell count and PCNA protein analysis, it was determined that GDF- 5 promoted EpSCs proliferation in vitro and in vivo.

FOX and cyclin have important functions in the proliferation of many cell types [21,38]. Firstly, we screened several subfamilies of the FOX family and cyclins related to cell proliferation by qPCR. Here, it was found that Foxg1 and cyclin D1 increased significantly (Fig. 2a). Wang Fan et al. found that cyclin D1 was significantly expressed during the proliferation of human EpSCs [29]. We previously reported that nitric oxide induces FoxG1 expression in human EpSCs [32]. In the analysis on GDF-5 promoting EpSCs proliferation, we found that Foxg1 and cyclin D1 could have prevented the proliferation effect of GDF-5 (Figs. 3c, d and 4); further analysis from the protein level found that Foxg1 and cyclin D1 were positively regulated by GDF-5 (Figs. $2 \mathrm{~b}$ and $3 \mathrm{e}$ ). Federica Verginelli et al. found that a transcriptional program regulated by Foxg1 is significant for promoting glioblastoma growth [39]. Combined with the results of in vivo and in vitro studies, this indicated that after GDF-5 stimulates EpSCs; the downstream molecules Foxg1 and cyclin D1 were activated (Fig. 6).

Besides, Foxg1 is involved in inhibiting the cell cycle exit initiated by p21 [27]. Cyclin D1 is a key regulator of cell proliferation by promoting cell cycle transition, and its expression is regulated by transcription level [40, 41]. To clarify the upstream and downstream relationship between Foxg1 and cyclin D1, dual-luciferase reporter gene analysis was used, and we found that GDF-5 induced cyclin D1 transcription was regulated by Foxg1-mediated cyclin D1 promoter activity (Fig. 5c, d). There may be other signaling pathways for GDF-5 to promote EpSCs proliferation. From Fig. 2a, discovered Foxo3/Foxp1 decreased significantly and cyclin D2/cyclin D3 increased significantly at the transcription level. Foxo3 and Foxp1 have been reported to play an inhibitory role in cell proliferation [19], and cyclin D2/cyclin D3 helps isolate cell transplant factor p27 [42]. Whether GDF- 5 regulates these genes to promote the proliferation of EpSCs will be analyzed in another project.

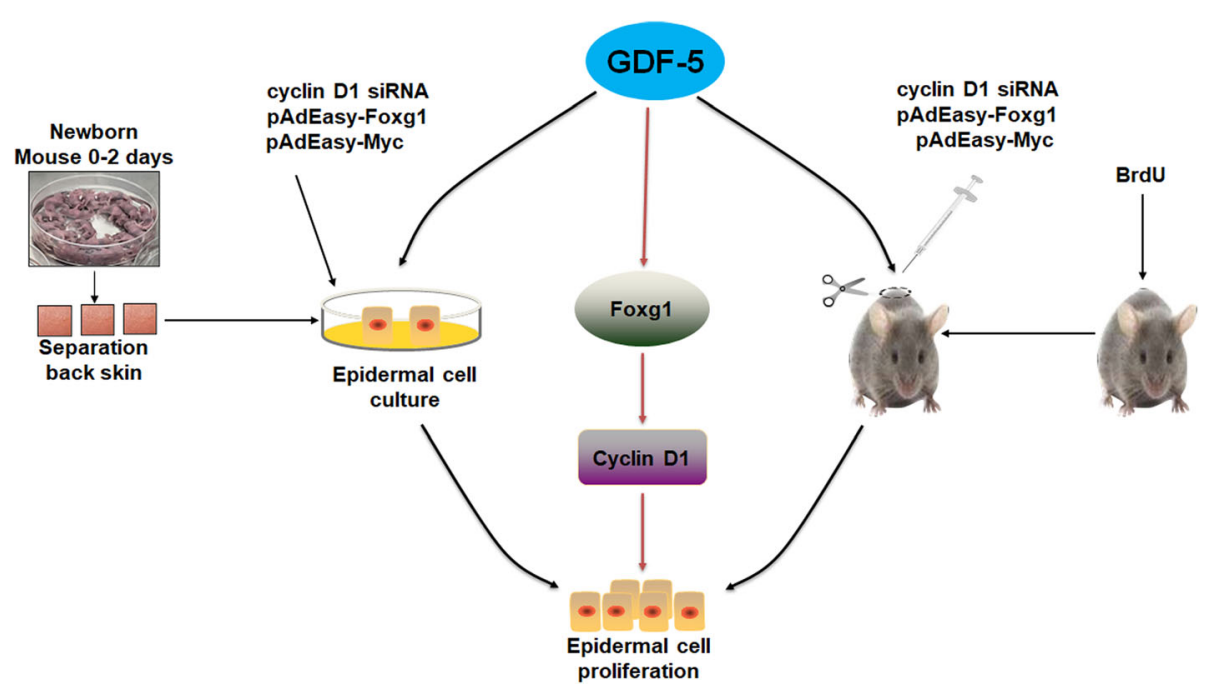

Fig. 6 GDF-5 promotes epidermal stem cell proliferation via Foxg1-cyclin D1 signaling 


\section{Conclusions}

This study shows that GDF-5 plays an important role in EpSCs proliferation in vitro and in vivo. The proliferation is regulated by activating Foxg1-cyclin D1 signaling pathway. The results can initially determine that GDF-5 can be used as a new target for wound repairing.

\section{Abbreviations}

EpSCs: Epidermal stem cells; GDF-5: Growth/differentiation factor 5; MAPK: Mitogen-activated protein kinase; PCNA: Proliferating Cell Nuclear Antigen; Wnt: Wingless/Integrated; BMP: Bone morphogenetic protein; FOX: Fork head box; TGF- $\beta$ : Transforming growth factor-beta; CDK: (4 or 6) Cyclin-dependent kinase 4 or 6; BPE: Bovine pituitary extract; CCK-8: Cell counting kit-8; qPCR: Real-time quantitative PCR; WB: Western blotting; FC: Flow cytometry; PI3K-AKT/PKB: Phosphoinositide-3-kinase-protein kinase $\mathrm{B} / \mathrm{Akt}$

\section{Authors' contributions}

Xiaohong Zhao and Ruyu Bian performed the experiments and analyzed the data. Fan Wang and Ying Wang guided the WB and immunofluorescence assay. Xue Li, Yicheng Guo, and Xiaorong Zhang made the necessary corrections in the write-up. Gaoxing Luo and Rixing Zhan conceptualized and guided the research project. All authors proofread the manuscript. The authors read and approved the final manuscript.

\section{Funding}

This work was supported by Chongqing Science and Health Joint Medical Research Project in 2020 (2020MSXM001) and the National Natural Science Foundation of China (81920108022).

\section{Availability of data and materials}

The data that support the findings of this study are available from the corresponding author upon reasonable request.

\section{Ethics approval and consent to participate}

All animal procedures were approved by the Committee on the ethics of Animal Experiments of the Third Military Medical University and were conducted in accordance with the guidelines of the Experimental Animal Department of the Army Military Medical University (Animal use protocol approval number: amuwec20201412).

\section{Consent for publication}

All patients signed a consent form for their data to be used for research or publication.

\section{Competing interests}

The authors declare no competing financial interest.

\section{Author details}

${ }^{1}$ Institute of Burn Research; State Key Laboratory of Trauma, Burn and Combined Injury; Southwest Hospital, The Third Military Medical University (Army Medical University), Chongqing 400038, China. ${ }^{2}$ Department of Plastic and Reconstructive Surgery, Southwest Hospital, The Third Military Medical University (Army Medical University), Chongqing 400038, China.

Received: 30 October 2020 Accepted: 15 December 2020 Published online: 07 January 2021

\section{References}

1. Beck B, Blanpain C. Mechanisms regulating epidermal stem cells. EMBO J. 2012;31(9):2067-75.

2. Horst BT, Chouhan G, Moiemen NS, Grover LM. Advances in keratinocyte delivery in burn wound care. Adv Drug Deliv Rev. 2017;123:18-32.

3. Iwata Y, Akamatsu H, Hasebe Y, Hasegawa S, Sugiura K: [Skin-resident stem cells and wound healing] Nihon Rinsho Men'eki Gakkai kaishi 2017, 40(1):1-11.

4. Billingham RE, Reynolds J. Transplantation studies on sheets of pure epidermal epithelium and on epidermal cell suspensions. Br J Plast Surg. 1952;5(1):25-36

5. Li Y, Zhang J, Yue J, Gou X, Wu X. Epidermal stem cells in skin wound healing. Advances Wound Care. 2017;6(9):297-307.
6. Hu P, Yang Q, Wang Q, Shi C, Wang D, Armato U, Prà ID, Chiarini A Corrigendum to: 'Mesenchymal stromal cells-exosomes: a promising cellfree therapeutic tool for wound healing and cutaneous regeneration'. Burns Trauma. 2020;8:tkaa007.

7. Li Z, Maitz P. Cell therapy for severe burn wound healing. Burns Trauma. 2018:6(2):72-81.

8. Chen RE, Thorner J. Function and regulation in MAPK signaling pathways: lessons learned from the yeast Saccharomyces cerevisiae. Biochimica et Biophysica Acta (BBA) - Molecular Cell Research. 2007; 1773(8):1311-40.

9. Zhu AJ, Haase I, Watt FM. Signaling via $\beta 1$ integrins and mitogen-activated protein kinase determines human epidermal stem cell fate in vitro. Proc Natl Acad Sci U S A. 1999:96(12):6728-33.

10. Veltri A, Lang C, Lien WH. Concise review: Wnt signaling pathways in skin development and epidermal stem cells. Stem Cells. 2018;36(1):22-35.

11. Thompson CC, Sisk JM, 3rd BG: Hairless and Wnt signaling: allies in epithelial stem cell differentiation. Cell Cycle 2006, 5(17):1913.

12. Wang RN, Green J, Wang Z, Deng Y, Qiao M, Peabody M, Zhang Q, Ye J, Yan Z, Denduluri S et al. Bone Morphogenetic Protein (BMP) signaling in development and human diseases. Genes Dis. 2014;1(1):87-105.

13. Schiefer JL, Held M, Fuchs PC, Demir E, Plöger F, Schaller HE, RahmanianSchwarz A. Growth differentiation factor 5 accelerates wound closure and improves skin quality during repair of full-thickness skin defects. Adv Skin Wound Care. 2017;30(5):223-9.

14. $X X$ Q, Li TG, Hao J, Hu J, Wang J, Simmons H, Miura S, Mishina Y: BMP4 supports self-renewal of embryonic stem cells by inhibiting mitogenactivated protein kinase pathways. Proc Natl Acad Sci U S A. 2004;101(16): 6027-32.

15. Zaidi SHE, Huang Q, Momen A, Riazi A, Husain M. Growth differentiation factor 5 regulates cardiac repair after myocardial infarction. J Am Coll Cardiol. 2010;55(2):135-43.

16. Chen X, Zankl A, Niroomand F, Liu Z, Katus HA, Jahn L, Tiefenbacher C: Upregulation of ID protein by growth and differentiation factor 5 (GDF5) through a smad-dependent and MAPK-independent pathway in HUVSMC. J Molecular Cell Cardiol 2006, 41(1):0-33.

17. Nakahara T, Tominaga K, Koseki T, Yamamoto M, Yamato K, Fukuda J, Nishihara T. Growth/differentiation factor-5 induces growth arrest and apoptosis in mouse B lineage cells with modulation by Smad. Cell Signal. 2003;15(2):181-7.

18. Zeng Q, Li X, Beck G, Balian G, Shen FH: Growth and differentiation factor-5 (GDF-5) stimulates osteogenic differentiation and increases vascular endothelial growth factor (VEGF) levels in fat-derived stromal cells in vitro. Bone 2007, 40(2):0-381.

19. Charvet C, Alberti I, Luciano F, Jacquel A, Bernard A, Auberger P, Deckert M. Proteolytic regulation of Forkhead transcription factor FOXO3a by caspase3-like proteases. Oncogene. 2003;22(29):4557-68.

20. Myatt SS, Lam EWF. The emerging roles of forkhead box (Fox) proteins in cancer. Nat Rev Cancer. 2007;7(11):847-59.

21. Katoh M, Katoh M. Human FOX gene family (review). Int J Oncol. 2004;25(5): 1495-500

22. Seoane J, Le H-V, Shen L, Anderson SA, Massagué J. Integration of Smad and Forkhead pathways in the control of neuroepithelial and glioblastoma cell proliferation. Cell. 2004;117(2):211-23.

23. Zheng X, Lin J, Wu H, Mo Z, Lian Y, Wang P, Hu Z, Gao Z, Peng L, Xie C. Forkhead box (FOX) G1 promotes hepatocellular carcinoma epithelialmesenchymal transition by activating Wnt signal through forming T-cell factor4/Beta-catenin/FOXG1 complex. J Experimental Clin Cancer Res. 2019:38(1):475

24. Zhang S, Zhang Y, Dong Y, Guo L, Zhang Z, Shao B, Qi J, Zhou H, Zhu W, Yan $X$, et al. Knockdown of Foxg1 in supporting cells increases the transdifferentiation of supporting cells into hair cells in the neonatal mouse cochlea. Cell Molecular Life Sci. 2020;77(7):1401-19.

25. Pestell RG. New roles of cyclin D1. Am J Pathol. 2013;183(1):3-9.

26. Witzel I-I, Koh LF, Perkins ND. Regulation of cyclin D1 gene expression. Biochem Soc Trans. 2010;38(1):217.

27. Siegenthaler JA, Tremper-Wells BA, Miller MW. Foxg1 haploinsufficiency reduces the population of cortical intermediate progenitor cells: effect of increased p21 expression. Cereb Cortex. 2008;18(8):1865-75.

28. Zhao A, Yang L, Ma K, Sun M, Li L, Huang J, Li Y, Zhang C, Li H, Fu X. Overexpression of cyclin D1 induces the reprogramming of differentiated epidermal cells into stem cell-like cells. Cell cycle (Georgetown, Tex). 2016; 15(5):644-53. 
29. Wang F, Zhan R, Chen L, Dai X, Cao C. RhoA promotes epidermal stem cell proliferation via PKN1-cyclin D1 signaling. PLoS One. 2017;12(2):e0172613.

30. Tudor D, Chaudry F, Harper L, Mackenzie IC. The in vitro behavior and patterns of colony formation of murine epithelial stem cells. Cell Prolif. 2007; 40(5):706-20.

31. Yao Z, Li H, He W, Yang S, Zhang X, Zhan R, Xu R, Tan J, Zhou J, Wu J. P311 accelerates skin wound reepithelialization by promoting epidermal stem cell migration through RhoA and Rac1 activation. Stem Cells Development. 2017;26(6):451-60.

32. Zhan, Rixing, Wang, Fan, Wu, Ying, Qian, Wei, Liu, Menglong: Nitric oxide promotes epidermal stem cell proliferation via FOXG1-c-Myc signalling. Nitric Oxide Biol Chemistry 2018.

33. Zhao X, Zou X, Li Q, Cai X, Li L, Wang J, Wang Y, Fang C, Xu F, Huang Y, Total flavones of fermentation broth by co-culture of Coprinus comatus and Morchella esculenta induces an anti-inflammatory effect on LPS-stimulated RAW264.7 macrophages cells via the MAPK signaling pathway. Microb Pathog. 2018;125:431-7.

34. Zhan R, He W, Wang F, Yao Z, Tan J, Xu R, Zhou J, Wang Y, Li H, Wu J. Nitric oxide promotes epidermal stem cell migration via cGMP-rho GTPase signalling. Sci Rep. 2016;6(1):30687.

35. Xu ZD, Li HS, Wang S, He WF, Wu J, Luo GX: [Effects of hypoxia inducible factor-1a on P311 and its influence on the migration of murine epidermal stem cells]. Zhonghua shao shang za zhi = Zhonghua shaoshang zazhi 2017, 33(5):287-294.

36. Lee KY, Myung K. PCNA modifications for regulation of post-replication repair pathways. Molecules Cells. 2008;26(1):5-11.

37. Coleman CM, Vaughan EE, Browe DC, Mooney E, Howard L, Barry F. Growth differentiation factor-5 enhances in vitro mesenchymal stromal cell chondrogenesis and hypertrophy. Stem Cells Dev. 2013;22(13):1968-76.

38. Vezzali R, Weise SC, Hellbach N, Machado V, Heidrich S, Vogel T. The FOXG1/FOXO/SMAD network balances proliferation and differentiation of cortical progenitors and activateskcnh3expression in mature neurons. Oncotarget. 2016;7(25):37436-55.

39. Verginelli F, Perin A, Dali R, Fung KH, Stifani S. Transcription factors FOXG1 and Groucho/TLE promote glioblastoma growth. Nat Commun. 2013;4:2956.

40. Hernández-Hernández OT, Camacho-Arroyo I. Regulation of gene expression by progesterone in cancer cells: effects on cyclin D1, EGFR and VEGF. Mini Rev Med Chem. 2013;13(5):635-42.

41. Wee P, Wang Z. Epidermal growth factor receptor cell proliferation signaling pathways. Cancers. 2017;9(5):52.

42. Chiles T. C: regulation and function of cyclin D2 in B lymphocyte subsets. J Immunol. 2004;173(5):2901-7.

\section{Publisher's Note}

Springer Nature remains neutral with regard to jurisdictional claims in published maps and institutional affiliations.

Ready to submit your research? Choose BMC and benefit from:

- fast, convenient online submission

- thorough peer review by experienced researchers in your field

- rapid publication on acceptance

- support for research data, including large and complex data types

- gold Open Access which fosters wider collaboration and increased citations

- maximum visibility for your research: over $100 \mathrm{M}$ website views per year

At $\mathrm{BMC}$, research is always in progress.

Learn more biomedcentral.com/submissions 